\title{
Correction to: Periprosthetic fractures after medial unicompartmental knee arthroplasty: a narrative review
}

\author{
L. Thoreau ${ }^{1}$ (D) D. Morcillo Marfil ${ }^{1} \cdot$ E. Thienpont ${ }^{1}$
}

Published online: 9 August 2021

○) Springer-Verlag GmbH Germany, part of Springer Nature 2021

\section{Correction to: Archives of Orthopaedic and Trauma Surgery https://doi.org/10.1007/s00402-021-04063-z}

The original version of this article unfortunately contained a mistake in the Ethics Declarations.

The correct information is given below.

The article incorrectly stated that the authors have no conflict of interest. Dr. Thienpont reports personal fees from Convatec, personal fees from KCI, personal fees from Lima, personal fees from Medacta, personal fees from Zimmer Biomet, and personal fees from Fidia, all outside the submitted work; In addition, Dr. Thienpont has a patent with Conformis with royalties paid, a patent with Lima with royalties paid, a patent with Medacta with royalties paid, and a patent with Zimmer Biomet with royalties paid.

Publisher's Note Springer Nature remains neutral with regard to jurisdictional claims in published maps and institutional affiliations.
The original article can be found online at https://doi.org/10.1007/ s00402-021-04063-z.

L. Thoreau

loic.thoreau@uclouvain.be

1 Department of Orthopedic Surgery, Cliniques Universistaires Saint Luc, Avenue Hippocrate 10, 1200 Brussels, Belgium 